$10 \%$ had signs of neurotic disorders

o $3 \%$ had alcohol-related problems

3.4\% had psychotic states.

\section{Study on disabilities}

A cross-sectional study to detect the number of children with disabilities was carried out in 2003. Of the 2834 children with disability examined, $63.8 \%$ had intellectual impairment.

\section{Joint Child Health Project}

A longitudinal study has been carried out in Mauritius from 1972 onwards. Initially it was designed to identify people at risk for schizophrenia and to take preventive measures. Several papers have been published (e.g. Raine et al, 2003).

\section{Study on suicide}

In a study on suicide carried out in 1995, the annual suicide rate was reported to be 8 per 100000 population in the 12 to 20-year age group, 10 per 100000 for all age groups and 14 per 100000 in the elderly age group.

\section{Private sector}

Psychiatric services in the private sector are provided by the government psychiatrists on a part-time basis and by three full-time private psychiatrists. There is no provision for involuntary admission in the private sector.

\section{Non-governmental organisations}

There are non-governmental organisations (NGOs) active in the private sector. For example, the only rehabilitation centre for people with serious mental illness is run by an NGO. There are few centres run for people with intellectual disabilities. 'Befrienders' are active and give support to people in distress.

\section{The way ahead}

Psychiatric services have seen tremendous changes in the past 8 years. The Lunacy Act of 1906 was repealed and replaced by the Mental Health Act 1998, which introduced voluntary care for psychiatric patients. With the implementation of the proposed amendments to the law and the dynamic National Strategic Plan for Mental Health, clear targets have been set. Encouraging public-private partnership is an area to be explored, mainly for rehabilitation and the relocation of long-stay patients. Recruiting the services of relatives as carers with financial incentives is another promising aspect to be looked at, as it will be cost-effective, the state having to spend more to keep the patient in the hospital than in the community. With increased personnel we hope to establish adequate community care and provide comprehensive psychiatric services to the population.

\section{Sources and references}

Raine, A., Mellinghan, K., Lui, J., et al (2003) Effects of environmental enrichment on schizotypal personality and antisocial behaviour. American Journal of Psychiatry, 160, 1627-1635.

Republic of Mauritius web portal, http://www.gov.mu (last accessed 19 April 2007)

US Central Intelligence Agency World Factbook, https://www.cia.gov/cia/ publications/factbook/geos/mp.html (last accessed 19 April 2007)

\title{
Mental health services in Tajikistan
}

\section{Alisher Latypov ${ }^{1}$ MA MHS, Vladimir Magkoev² MD, Mutabara Vohidova ${ }^{3}$ MD and Zulfia Nisanbaeva ${ }^{4} \mathrm{MD}$}

\begin{abstract}
${ }^{1}$ Country Manager in Tajikistan, Global Initiative on Psychiatry; Sub-regional Drug Epidemiology Expert, United Nations Development Programme, email alisher_latypov@fulbrightweb.org ${ }^{2}$ Narcology Specialist, Drug Demand Reduction Programme ${ }^{3}$ National Project Officer, United Nations Office on Drugs and Crime Sub-Office in Tajikistan ${ }^{4}$ Lecturer, Department of Psychiatry, Tajik State Medical University (Avicena); Chair, In-patient Forensic Psychiatry Commission
\end{abstract}

\begin{abstract}
ajikistan, in Central Asia, gained its independence in 1991, with the break-up of the Soviet Union. There followed a period of civil war, 1992-97. In 2003, 64\% of Tajikistan's population was poor, which was defined as living on less than US\$2.15 per day at purchasing power parity by the UN Appeal for Tajikistan (2006). The Tajik healthcare budget appropriations decreased from $4.5 \%$ of gross domestic product in 1991 to $1.3 \%$ in 2005 . The average annual rate of population growth is $2.19 \%$. The
\end{abstract}

estimated 7320815 population of the country is mainly rural $(73.5 \%)$ and about $38 \%$ of the country's population is under the age of 14. Life expectancy at birth is 62 years for males and 68 years for females. The infant mortality rate is 106.49 deaths per 1000 live births.

Tajikistan has a state-regulated system of healthcare which increasingly depends on unofficial private payments for medical services (70\% of total spending in recent years). In 2005, Tajikistan presented its draft National Development 
Strategy with three fundamental priorities: public administration reform, private sector development, and development of human potential. The main priorities for development of the healthcare system in Tajikistan are:

o reform of the healthcare system, including development of the private sector and attraction of investment

o improvement of maternal and child health

O a significant slow-down in the spread of HIV/AIDS, a reduction in infectious diseases and the eradication of certain infections that can be controlled by vaccination

O improved availability, quality and effectiveness of medical services (National Development Strategy, 2006).

\section{Mental health policy and legislation}

The legal framework for public health-related activities is the Law of the Republic of Tajikistan 'On Protection of Health of the Population', of 15 May 1997. It contains, inter alia, some provisions dealing with mental health. According to article 53 of this law, people with mental illnesses are categorised as those who 'pose a threat to surrounding people', along with people with tuberculosis, sexually transmitted diseases, leprosy, AIDS and other infections.

Activities in the field of mental healthcare provision have not been specifically regulated up to 2002 from the legal point of view. At present, these are governed by the Law of the Republic of Tajikistan 'On Psychiatric Care', adopted on 2 December 2002. Furthermore, there is a Decree of the Ministry of Health of Tajikistan, 'On Measures for Further Improvement of Psychiatric Care', of 9 February 2001, which approved 17 regulations on the provision of psychiatric care.

The only document which has an element of strategy on mental health in Tajikistan is the Strategy of the Republic of Tajikistan on Protection of Health of the Population for the Period to 2010. Task 6 of this strategy is entitled 'Improvement of Mental Health' and is aimed at improving significantly, by 2010, psychosocial support for the general population and people with mental disorders and ensuring improvement in the psychosocial status of people. This envisages:
O implementation of comprehensive measures on reduction of prevalence of mental disorders, and improvement of people's capacities to cope with life stressors

O establishment of comprehensive care services for people with mental disorders.

In 2005, at the Ministerial Conference in Helsinki, the Tajik Minister of Health signed the European Declaration and Action Plan on Mental Health.

\section{History of psychiatry in Tajikistan}

By the 1990s, a network of psychiatric institutions, including dispensaries, hospitals and mental health offices, had been established in Tajikistan. In-patient care was by far the predominant form of psychiatric service available, and hospital stay tended to be long. In the process of treatment of mental disorders, preference was given to biomedical interventions, such as psychopharmacotherapy or shock therapy.

The condition of post-Soviet mental health services in Tajikistan can be defined as critical, based on many indicators: availability of the qualified staff; provision of food; the state of the wards, facilities and utilities at the mental health institutions; and the availability of effective therapies. In 1996, in psychiatric hospitals of Lakkon and Leninsky districts, 311 of about 700 patients died mainly because of lack of food. The physical infrastructure of the mental health services was dilapidated. In many psychiatric care facilities there were no decent windows or doors; in-patients slept on beds with no mattresses, while dressed. There was little regard for basic hygiene (Médecins Sans Frontières, 2003).

Since 2005, first in-patient and then out-patient psychosocial rehabilitation programmes have been introduced by the Global Initiative on Psychiatry.

\section{Incidence and prevalence of mental disorders}

The Tajik Ministry of Health has provided the quantitative data on mental disorder shown in Table 1.

Table 1 Prevalence and incidence of mental and behavioural disorders in the Republic of Tajikistan as registered by the psychiatric services, 2001-05

\begin{tabular}{|c|c|c|c|c|c|c|}
\hline Mental and behavioural disorders & ICD-10 block & 2001 & 2002 & 2003 & 2004 & 2005 \\
\hline \multicolumn{7}{|l|}{ Prevalence } \\
\hline Total & F00-F09, F20-F99 & 39634 & 41300 & 40998 & 40951 & 41177 \\
\hline Schizophrenia, schizotypal and delusional disorders & F20-F29 & 10654 & 10805 & 10938 & 11069 & 11219 \\
\hline Mood disorders & F30-F39 & 656 & 685 & 673 & 673 & 688 \\
\hline Neurotic, stress-related and somatoform disorders & F40-F48 & 1681 & 1668 & 1688 & 1782 & 1699 \\
\hline $\begin{array}{l}\text { Behavioural syndromes associated with physiological disturbances and } \\
\text { physical factors; and disorders of adult personality and behaviour }\end{array}$ & F50-F69 & 1192 & 1198 & 1202 & 1210 & 1227 \\
\hline Mental retardation & F70-F79 & 19390 & 20341 & 20015 & 20230 & 20408 \\
\hline \multicolumn{7}{|l|}{ Incidence } \\
\hline Total & F00-F09, F20-F99 & 1402 & 1388 & 1370 & 1338 & 1406 \\
\hline Schizophrenia, schizotypal and delusional disorders & F20-F29 & 351 & 386 & 418 & 450 & 491 \\
\hline Mood disorders & F30-F39 & 37 & 23 & 16 & 26 & 28 \\
\hline Neurotic, stress-related and somatoform disorders & F40-F48 & 38 & 43 & 49 & 48 & 36 \\
\hline $\begin{array}{l}\text { Behavioural syndromes associated with physiological disturbances and } \\
\text { physical factors; and disorders of adult personality and behaviour }\end{array}$ & F50-F69 & 24 & 25 & 25 & 35 & 46 \\
\hline Mental retardation & F70-F79 & 629 & 691 & 569 & 543 & 563 \\
\hline
\end{tabular}

Source: Tajik Ministry of Health. 
Table 2 Total number of psychiatrists and narcologists in Tajikistan in 2003 and 2004, by region

$\begin{array}{lrr}\text { Region } & 2003 & 2004 \\ \text { Dushanbe City } & 72 & 70 \\ \text { Regions of Republican Subordinations } & 29 & 25 \\ \text { Sogd Region } & 58 & 54 \\ \text { Khatlon Region } & 26 & 25 \\ \text { Gorno-Badakhshan Autonomous Region } & 5 & 5 \\ \text { Total } & 190 & 179\end{array}$

Source: Tajik Ministry of Health.

\section{Mental health service delivery}

According to the Pharmaciens Sans Frontieres Comite International (PSFCl) report on the assessment of psychiatric institutions in the Republic of Tajikistan released in 2006:

there were 17 psychiatric institutions in the Republic of Tajikistan, divided in four groups of medical institutions with bed capacity i.e. psychiatric hospitals, psychoneurological dispensaries, psychoneurological centres and psychoneurological departments. Psychiatric departments within central district hospitals substitute for psychoneurological hospitals in districts with small populations. Therefore, there are in total 2 hospitals, 2 departments, 2 psychoneurological centres and 11 psychoneurological dispensaries in Tajikistan. PSFCI found that $69 \%$ of the hospitals' budget needs were not covered. Allocated State budget resources $(1,561,166.00$ Somoni or about 520,390.00 USD in 2005) were mainly intended to cover wages, food and medicines expenses. (PSFCl, 2006)

\section{Mental health workforce}

Institutionally, mental healthcare services in Tajikistan are provided within the public health and social sectors. According to the most recent (end of 2005) assessment of psychiatric institutions in Tajikistan, the evaluated structures were employing 102 doctors. Of those, 75 were psychiatrists and 27 were experts in narcology.

Table 2 provides Ministry of Health statistics on mental health professionals, including drug treatment specialists, by region in 2003 and 2004.

\section{Education and training}

Undergraduate and graduate medical and pharmaceutical education and training in Tajikistan are provided by the Tajik State Medical University named after Avicena. The overall duration of education and training of a medical doctor is between 7 and 8 years: basic medical education (bachelor's level) takes 5 years, and graduate (master's level) education is another 2-3 years.

Graduate training in psychiatry lasts 2 years. According to the syllabus, psychiatry-related courses take 882 hours per year or 1764 hours altogether over the 2 years of postgraduate training. The educational programme of other medical students also devotes some hours to psychiatry. This includes 1764 hours for drug treatment specialists, 60 hours for neurologists and 36 hours for general practitioners.

Medical education is multidisciplinary and the curriculum is developed in compliance with the state standard for graduate education in Tajikistan, approved by Resolution No. 95 of the Government of Tajikistan of 23 February 1996.

Postgraduate training of medical and pharmaceutical professionals is conducted by the Tajik Institute for Postgraduate Training of Medical Professionals, which was established in 1993. Such postgraduate 'upgrade' courses are to be undertaken by medical professionals every 5 years on a mandatory basis.

Training and education of nurses are provided by medical colleges and vocational schools.

\section{Substance misuse}

In 2002 the United Nations Office on Drugs and Crime (UNODC) estimated the number of drug users in Tajikistan at 45000-55000 (UNODC, 2002).

Specialised medical drug treatment in Tajikistan is provided exclusively by the narcological centres established in Soviet times. In 2005, 1040 individuals received in-patient treatment at such centres, of whom $96.4 \%$ were diagnosed with heroin addiction (F11.2 according to ICD-10). In 2001-05, the narcological facilities treated 4818 in-patients in total.

\section{Mental health and human rights}

According to a report from the Tajikistan Bureau on Human Rights, on access to psychiatric care in Tajikistan (Sanginov \& Romanov, 2006), violations of fundamental human rights are common in psychiatric institutions. In particular, the following are often not met: the right to information, notably regarding patients' rights; the right to equal reward for equal labour; the right to an adequate environment; the right to the best available treatment; economic and social rights.

Patient's participation in discussion of the treatment plan and the giving of informed consent for treatment are not in place, and patients play only a passive role. They are almost never informed of their diagnosis and their health condition (they are often told simply that they have developed a psychiatric illness).

Drinking water is often unavailable. There is a shortage of electricity, especially in winter. Daily schedules are repetitious; most patients have nothing to do but to sit and stare at the walls around them. Wards lack furniture except for metal beds. The freedom of movement of patients is very limited, even within the institutions.

Psychiatric patients do not have an opportunity to ask for alternative psychiatric examination. There is no institute of independent psychiatric expertise in Tajikistan (Sanginov \& Romanov, 2006).

\section{Conclusion}

Tajik psychiatry 'flourished' during Soviet times, when the biomedical approach to treatment was paramount. The collapse of that system and the subsequent civil war in Tajikistan led to a major emergency in psychiatry in terms of migration of qualified staff, dilapidation of buildings and disintegration of services. As Tajik society recovered from deep social and economic crisis, the provision of mental 
health services gradually stabilised. While the financial capacity of the government is still very limited, the Central Asian region as a whole, and Tajikistan in particular, are the focus of many international donors and non-governmental agencies. As some of them prioritise the social sector and in a few cases mental health, new psychosocial rehabilitation services are being developed and opportunities exist for further improvement of mental healthcare in Tajikistan.

\section{Sources and references}

Central Intelligence Agency. The World Fact Book, Tajikistan. See https:// www.cia.gov/cia/publications/factbook/geos/ti.html (last accessed 23 April 2007).
Médecins Sans Frontières (2003) 'Will You Remember Me?' A Question from the Patients of Psychiatric Institutions in Tajikistan. Report of Médecins Sans Frontières on the Situation in Psychiatric Institutions in the Republic of Tajikistan. Médecins Sans Frontières, Dushanbe, Tajikistan.

National Development Strategy of the Republic of Tajikistan for the Period to 2015, draft, 2006. See http://www.untj.org (last accessed 23 April 2007).

PSFCI (2006) Report on the Assessment of Psychiatric Institutions in the Republic of Tajikistan. PSFCl.

Sanginov, K. \& Romanov, S. (2006) Access to Psychiatric Care in Tajikistan. Tajikistan Bureau on Human Rights.

UN Appeal for Tajikistan (2006) See http://www.untj.org (last accessed 23 April 2007).

UNODC (2002) Regional Conference on Drug Abuse in Central Asia: Situation Assessment and Responses. Conference Report. UNODC.

\title{
Mental health legislation in contemporary India: a critical review
}

\author{
Kunal Kala ${ }^{1}$ and A. K. Kala ${ }^{2}$
}

1Specialist Registrar, Manchester, UK, email kunalkala@hotmail.com ${ }^{2}$ Consultant Psychiatrist, 95-A, Model Gram, Ludhiana 141002, India

\begin{abstract}
fter 20 years of experience with the legislation, it is now a good time to assess the Mental Health Act 1987 of India. How useful has it been to consumers, carers and the mental health profession? It has been perceived as isolationist because it deals only with psychiatric hospitals and excludes a large number of general hospital psychiatric units from its purview. It is also un-implementable in some parts of the country because of the shortage of resources. From a human rights perspective, it is deficient in two important ways: it failed to establish independent review bodies for involuntary admissions; and it lacks provision for research with people who have a mental illness.
\end{abstract}

\section{Historical background}

When Britain granted independence to India in 1947, it left behind a plethora of antiquated laws, including the Indian Lunacy Act of 1912, which used terms originating from that era, such as 'lunatic asylums', 'lunatics' and 'idiot'. Every involuntary admission had to be ordered by a magistrate and every discharge by a board of visitors, which met monthly. After independence, the law was found to be so unworkable that everybody cheerfully bypassed it for the next 40 years while work continued on and off on a new law, until the Mental Health Act 1987 replaced it.

However, implementation of that Act was impeded, both by administrative apathy and by resistance from mental health professionals, who perceived it as having or indeed promoting an isolationist approach to psychiatric patients, who had only recently started receiving the benefits of a resurgent general hospital psychiatry movement in the country (Kala, 1997).

\section{Judicial response to the Erwady trajedy, 2001}

On 7 August 2001, 25 people with a mental illness were burned to death in an accidental fire at night, while chained to pillars in a religious shrine in the Erwady district of Tamil Nadu in South India. These patients had been left by poor families in the care of the shrine management. The Supreme Court of India took 'suo moto' cognisance of the event and started a civil writ petition (no. 334 of 2001), which is still ongoing. The Supreme Court discovered that the regulatory provisions of the Mental Health Act were not being implemented in the country. The Court ordered country-wide implementation of the licensing and other provisions of the Mental Health Act and asked for compliance reports from each of the 34 states. The government complained that the number of mental health professionals in the country was so small that the norms required for licensing a psychiatric hospital, for example one psychiatrist per ten admitted patients, simply could not be met.

The Court then ordered uniform norms of care across both the public and the private sector and asked for a country-wide, state-wise survey to find out the exact number 